\title{
An Empirical Study of After-sales Service Relationship in China's Auto Industry
}

\author{
Wu Shuqin \\ Department of Management Science and Engineering, \\ Business School \\ East China University of Science and Technology, \\ ECUST, Shanghai, China \\ wsqlinda@126.com
}

\author{
Liu Gang \\ Department of Management Science and Engineering, \\ Business School \\ East China University of Science and Technology, \\ ECUST, Shanghai, China \\ liugang@ecust.edu.cn
}

\begin{abstract}
This research analyzed the current situation and future development trend in auto after-sales service industry. Then based on the five dimensions of service quality (fairness, empathy, reliability, responsiveness and convenience), three dimensions of relationship quality (satisfaction, trust and commitment), constructs a structural equation model to assess the relationship among service quality, relationship quality and relationship value. Researched on the samples from 327 customers in auto after-sales service industry, we found that fairness, empathy, reliability and convenience have significant positive impact on satisfaction, but responsiveness has no significant positive impact on satisfaction; at the same time satisfaction has a significant positive impact on trust, and trust has a significant positive impact on commitment. We also found satisfaction and commitment both have significant positive impact on relationship vale, but trust cannot influence relationship value directly.
\end{abstract} value

Keywords-service quality; relationship quality; relationship

\section{INTRODUCTION}

By the end of 2011, the vehicle ownership of China increased to 105.78 million, almost rose $16.4 \%$ than last year, including 78.72 million private cars, this will rise to 150 million in 2015. With the increasing of private cars, auto aftersales market also develop rapidly, expect to reach 490 billion in 2012. Such a great potential market attracts more and more businesses get into the auto after-sales market to seek new business opportunities. But compared with foreign developed countries, domestic automobile market is still in a primary stage, the scale of the service providers is different, and service quality also is different, so it is not conducive to the long-term development of automobile service industry. Therefore, it needs to research on customer perception of service quality in this industry, helps enterprise improve customer service system, provide higher service quality for customers, in order to keep customers, extend the relationship duration, create greater profit for the service providers.

In auto after-sales context, this study bases on the concept of relationship quality in relationship marketing, researched on the service relationship between automotive service provider and customer. Put forward five practical dimensions of service

Sponsored by Humanities and Social Sciences Project of the Ministry of Education in China (No.10YJA790112) quality in the auto after-sales industry, study how they influence relationship value through three dimensions of relationship quality, including satisfaction, trust, commitment. From the perspective of customer, explored how the customer perception of service quality influence the customers satisfaction to auto service providers, then we studied the relationship among different relationship quality dimensions and how they influence the value that service providers could get.

\section{CONCEPTUAL FRAMEWORK}

\section{A. Service Quality (SQ)and Relationship Quality (RQ)}

Service quality has also been defined as the result of a comparison between the received service and the expected service (Grönroos, 1984). Keaveney (1995) noted that empirical research in service industry, suggesting that service provider's service quality has important influence on whether customer will switch to other providers, if the provider can provide high quality service, that will improve customer satisfaction, so he/ she can establish long-term relationship with customers, customers will also be willing to continue to accept service from this service provider. Some scholars had proved the obvious causality between service quality and customer satisfaction. Cronin and Taylor (1992) research 660 samples from 8 companies in four industries, using structural equation method to analyze the relationship between satisfaction, service quality and purchase intention, they found service quality is the antecedent of relationship satisfaction. Other scholars used the modified satisfaction/service quality model, we study the relationship between service quality and satisfaction, in this fixed model, proved they are correlated.

A number of foreign scholars had found service quality is a high-order concept. Andaleeb and Basu (1994) pointed out that customer perception of service quality in auto service industry, including fairness (FAI), empathy (EMP), responsiveness (RES), reliability (REL), convenience (CON). There are three dimensions of relationship quality, including satisfaction (SAT), trust (TRU), commitment (COM).

The concept of fairness comes from the exchange theory and equity theory, defining fairness as parties believe distributive are justice, that everyone got it want. Han Xiaoyun 
and Wang Xiaochun (2003) pointed out that service fairness can through the customer perception of service quality indirectly influence customer satisfaction. Therefore, the following hypothesis is provided:

H1a : Service fairness (FAI) has a significant positive impact on satisfaction (SAT)

Empathy argues service providers pay attention to customer's individual needs and provide customers with special attention. Many scholars have proved staff's empathy to the customer is higher; the customer satisfaction to the enterprise service is higher. Therefore, the following hypothesis is provided:

H1b: Service empathy (EMP) has a significant positive impact on satisfaction (SAT)

Responsiveness is an important determining factors of service quality, service responsiveness refers to service personnel is willing to help customers and to provide customers with timely efficient service .Lee and Yoo (2000) used 521 samples from three industries (amusement park/ school/ investment consulting company), through the empirical research they found service responsiveness has positive impact on satisfaction. Therefore, the following hypothesis is provided:

H1c : Service responsiveness (RES) has a significant positive impact on satisfaction (SAT)

Reliability refers to provide service responsibly and precisely as they promised. Sullivan (1996) pointed out regardless of any type of consumers, the customer satisfaction was influenced by service reliability obviously .Therefore, the following hypothesis is provided:

H1d: Service reliability (REL) has a significant positive impact on satisfaction (SAT)

Brown (1990) suggested that convenience consists of the time and effort consumers expend on product and service acquisition and consumption. In the new economic era, customers pay more and more attention to time; they do not want to waste time on unnecessary activities. If the process that customer get service is not convenient, they may switch to other providers. Therefore, the following hypothesis is provided:

H1e : Service convenience (CON) has a significant positive impact on satisfaction (SAT)

\section{B. Relationship Quality and Relationship Value}

Customer's feeling of satisfaction is a result of a comparison process between perceived performance and expectations. Trust is defined as one party's belief that its needs will be fulfilled in the future by actions taken by the other party. Satisfaction and trust both represent the overall evaluation, feeling and attitude to the other party in the relationship. Ravald and Grönroos (1996) pointed out trust is advanced than satisfaction when assess a relationship. In fact, satisfaction is an important source of trust. Trust and satisfaction both originate from the past experience, but trust has a specific picture for future. In conclusion, satisfaction is the precursor of trust in a continuous relationship. Therefore, the following hypothesis is introduced:

H2a: Satisfaction (SAT) has a significant positive impact on trust (TRU)

Commitment refers to an enduring desire to maintain a valued relationship. In the relationship context, trust and commitment have been regarded as the key variables, which can influence the success of relationship exchanges. At the same time they are both the important factors to extend relationship duration. According to trust and commitment theory proposed by Morgan and Hunt (1994), trust and commitment both are mediating variables; also emphasizing trust is antecedent of commitment. Because commitment means the potential damage and sacrifice, no one can easily make a promise, only when trust is established, commitment will emerge. Therefore the following hypothesis is introduced:

$\mathrm{H} 2 \mathrm{~b}$ : Trust (TRU) has a significant positive impact on commitment (COM)

\section{Relationship Quality (rq)and Relationship Value(RV)}

Relationship value is understood as the value generated from the relationship between two parties when we compare all benefits and sacrifices. Relationship value is the result of having cultivated long-term relationships with a service provider, being above and beyond the core service performance.

Crosby et al. (1990) used the empirical research method, and found high relationship quality can make consumer believe that service provider is honest. If the customer feels trust and satisfaction in service personnel, which will improve sales and promote the interaction between the customer and service provider, the customer, will continue this business relationship with provider, it will create greater value for provider. Some scholars pointed out provider maintain a good relationship quality with customer can improve customer positive behavioral intention, reduce negative behavior intention. Ryssel et al. (2004) found that trust and commitment both have positive correlation with direct and indirect value; composite elements of relationship quality can not only affect the shortterm benefits, but also influence provider long-term benefits. Therefore, the following hypotheses are provided:

H3a: Satisfaction (SAT) has a significant positive impact on relationship value $(\mathrm{RV})$

$\mathrm{H} 3 \mathrm{~b}$ : Trust (TRU) has a significant positive impact on relationship value (RV)

$\mathrm{H} 3 \mathrm{c}$ : Commitment (COM) has a significant positive impact on relationship value (RV)

The inferential relationships among the constructs displayed in Fig1, where then tested through the use of structural equation modeling, the results of which are presented in the last subsection of our analyses. 


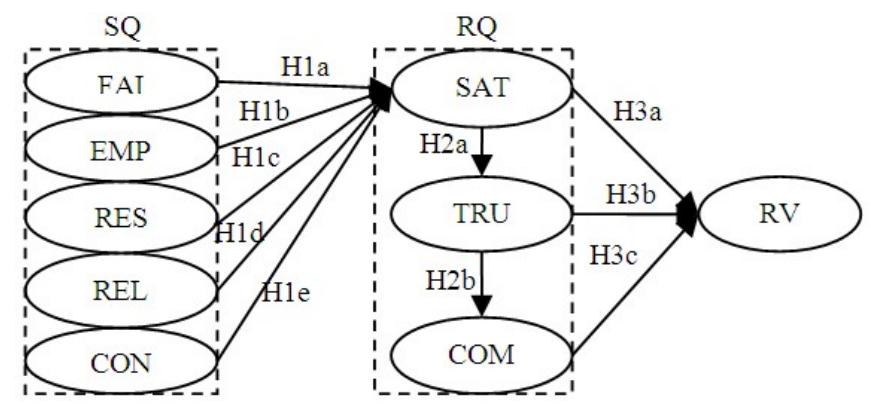

Figure 1.Conceptual Model

\section{RESEARCH METHOD}

\section{A. Scale Development and Measures}

In developing the scale items for each of the five dimensions of service quality in automobile service industry, we followed the guidelines provided by Andaleeb and Basu (1994).We analyzed relationship quality, comparing these qualitative data to the three domains, the revised items proposed by Geyskens and Steenkamp(2000), Zeithaml and Berry(1996), Morgan and Hunt(1994). Relationship value scale items proposed by Stahl (2003). All items are seven-point Likert -type, ranging from "strongly disagree", 1 to "strongly agree", 7 .

\section{B. Sample and Data Collection}

This study was conducted in Shanghai and Tianjin, a total of 327 valid questionnaires were obtained. Among the samples collected, male respondents $(72.8 \%)$ were majority. In terms of education background, junior college degree or above customers accounted for $85.9 \%$.In terms of use time, below 1 year $(18.04 \%), 1-3$ years $(53.82 \%), 3-5$ yeasrs $(19.27 \%)$, above 5 years $(8.87 \%)$.

\section{Construct Reliability and Validity}

This research used SPSS software (version 11.5) to perform construct reliability and validity. We found all of the indicators Cronbach's $\alpha$ fulfill the criteria 0.70 . The composite reliabilities for service quality, relationship quality and relationship even exceed 0.90 , as shown in table1.This study used items proposed by other scholars; we also revised items after practical survey of enterprise, so the questionnaire has good content validity. The indicator KMO $0.928(>0.70)$, Bartlett was significant $(\mathrm{p}=0.000<0.0001)$. Factor analysis results see Tab I, corresponding factor loading are above 0.7 , indicating that the questionnaire has good construct validity.

TABLE I. RELIABILITY AND VALIDITY

\begin{tabular}{|c|c|c|}
\hline Factor/Variable & Cronbach's $\boldsymbol{\alpha}$ & Loading \\
\hline Service quality(SQ) & 0.920 & \\
\hline Fairness(FAI) & 0.784 & 0.729 \\
\hline Empathy(EMP) & 0.791 & 0.814 \\
\hline Responsiveness(RES) & 0.747 & 0.785 \\
\hline Reliability(REL) & 0.853 & 0.794 \\
\hline Convenience(CON) & 0.798 & 0.709 \\
\hline Relationship quality(RQ) & 0.920 & \\
\hline Satisfaction(SAT) & 0.874 & 0.823 \\
\hline Trust(TRU) & 0.803 & 0.834 \\
\hline Commitment(COM) & 0.814 & 0.841 \\
\hline Relationship value(RV) & 0.912 & 0.834 \\
\hline
\end{tabular}

\section{Measurement Model Assessment Define abbreviation}

We assessed the structural model by using software AMOS (version 4.0). The model results $(\mathrm{X} 2 / \mathrm{df}=2.22$, GFI $=0.82$, $\mathrm{CFI}=0.90, \mathrm{RMSEA}=0.06$, PNFI $=0.75$ ) suggested a good fit of the model to the data, as shown in Tab II .But we find H1c and $\mathrm{H} 3 \mathrm{~b}$ are not supported, as shown in Tab III.

TABLE II. FIT STATISTICS FOR THE OVERALL MEASUREMENT MODEL

\begin{tabular}{|c|c|c|c|}
\hline Variable & Value & Variable & Value \\
\hline X2/df & 2.22 & NFI & 0.86 \\
\hline GFI & 0.82 & CFI & 0.90 \\
\hline RMSEA & 0.06 & PNFI & 0.75 \\
\hline AGFI & 0.80 & PCFI & 0.80 \\
\hline
\end{tabular}

TABLE III. SRUCTUAL MODEL

\begin{tabular}{|c|c|c|c|c|c|c|}
\hline Hi & Relationship & Estimate & S.E. & C.R. & $\mathbf{P}$ & Hi Supported \\
\hline H1a & Satisfaction(SAT) $\leftarrow$ Fairness(FAI) & 0.155 & 0.078 & 2.211 & $* *$ & Yes \\
\hline $\mathrm{H} 1 \mathrm{~b}$ & Satisfaction(SAT) $\leftarrow$ Empathy(EMP) & 0.365 & 0.144 & 3.048 & $* *$ & Yes \\
\hline H1c & Satisfaction(SAT) $\leftarrow$ Responsiveness(RES) & 0.035 & 0.119 & 0.290 & 0.772 & No \\
\hline H1d & Satisfaction(SAT) $\leftarrow$ Reliability(REL) & 0.209 & 0.123 & 2.133 & ** & Yes \\
\hline H1e & Satisfaction $(\mathrm{SAT}) \leftarrow$ Convenience $(\mathrm{CON})$ & 0.239 & 0.058 & 3.970 & $* * *$ & Yes \\
\hline $\mathrm{H} 2 \mathrm{a}$ & Trust(TRU) $\leftarrow$ Satisfaction(SAT) & 0.914 & 0.069 & 12.218 & $* * *$ & Yes \\
\hline $\mathrm{H} 2 \mathrm{~b}$ & Commitment(COM) $\leftarrow$ Trust(TRU) & 0.891 & 0.079 & 13.790 & $* * *$ & Yes \\
\hline $\mathrm{H} 3 \mathrm{a}$ & Relationship value $(\mathrm{RV}) \leftarrow$ Satisfaction(SAT) & 0.637 & 0.175 & 3.972 & $* * *$ & Yes \\
\hline $\mathrm{H} 3 \mathrm{~b}$ & Relationship value(RV) $\leftarrow$ Trust(TRU) & -0.254 & 0.270 & -1.109 & 0.267 & No \\
\hline $\mathrm{H} 3 \mathrm{c}$ & Relationship value $(\mathrm{RV}) \leftarrow$ Commitment $(\mathrm{COM})$ & 0.548 & 0.127 & 4.161 & $* * *$ & Yes \\
\hline
\end{tabular}




\section{RESULTS}

The results from hypotheses testing are also displayed in Tab2, where "Yes" represent significant $(p<0.05)$ relationship between constructs and "No" indicate the lack of a relationship. Hypotheses 1a $(p<0.05), 1 \mathrm{~b}(\mathrm{p}<0.05), 1 \mathrm{~d}(\mathrm{p}<0.05), 1 \mathrm{e}(\mathrm{p}<0.001)$ were supported, suggesting that fairness, empathy, reliability, convenience have a significant positive impact on satisfaction. Hypothesis1c was rejected, indicating responsiveness has no significant positive impact on satisfaction. Hypotheses $2 \mathrm{a}$ $(\mathrm{p}<0.001), 2 \mathrm{~b}(\mathrm{p}<0.001)$ were supported, suggesting that satisfaction has a significant positive impact on trust, as well as trust has a significant positive impact on commitment, and that three dimensions of relationship quality are in a progressive relation. Finally, hypotheses $3 a(p<0.001), 3 c(p<0.001)$ were supported, and hypothesis $3 \mathrm{~b}$ was rejected, indicating that satisfaction and commitment have significant positive impact on relationship value, but trust cannot influence relationship value directly.

This study provides a new direction for the after-sales service relationship research. We also found a suitable antecedent of after-sales service relationship quality. This study will provide abundant theoretical basis for future research.

\section{REFERENCES}

[1] Susan M. Keaveney, "Customer Switching Behavior in Service Industries: An Exploratory Study", 2nd ed., vol. 59. Journal of Marketing, 1995, pp. 71-82.

[2] Joseph Cronin, Jr, and Steven A. Taylor, "Measuring Service Quality: A Reexamination and Extension", 3rd ed., vol. 56. Journal of Marketing, 1992, pp. 55-68.

[3] Syed Saad Andaleeb, and Amiya K. Basu, "Technical Complexity and Consumer Knowledge as Moderators of Service Quality Evaluation in the Automobile Service Industry", 4th ed., vol. 70. Journal of Retailing, 1994, pp.367-381.
[4] Han Xiaoyun, and Wang Xiaochun,"The Relationship between Customer Satisfaction and Commitment in Service Enterprise “,Beijing, Tsinghua University Press

[5] Haksik Lee, Yongki Lee, and Dongkeun Yoo,"The determinants of perceived service quality and its relationship with satisfaction", 3rd ed., vol. 14. Journal of Services Marketing, 2000, pp. 217-231.

[6] Ravald,A.,and Grönroos, "The value concept and relationship marketing”, 2nd ed., vol. 30. European Journal of Marketing,1996, pp. 19-30..

[7] Robert M. Morgan, and Shelby D. Hunt., "The Commitment-Trust Theory of Relationship Marketing" 3rd ed., vol. 58. Journal of Marketing, 1994, pp. 20-38.

[8] Crosby L. A.,Evans K. R.,Cowles D, "Relationship Quality in Services Selling: An Interpersonal Influence Perspective", 3rd ed., vol. 54. Journal of Marketing, 1990, pp. 68-81.

[9] Inge Geyskens, and Jan-Benedict E. M. Steenkamp, "Economic and Social Satisfaction: Measurement and Relevance to Marketing Channel Relationships", 1st ed., vol. 76. Journal of Retailing, 2000, pp. 11-32

[10] Zeithaml V.,Berry L.,Parasuraman A., "The behavioral consequences of service quality”., 2nd ed., vol. 60. Journal of Marketing, 1996, pp. 31-46.

[11] Heinz K. Stahl, Kurt Matzler, Hans H. Hinterhuber, "Linking customer lifetime value with shareholder value" , 1st ed., vol. 32. Industrial Marketing Management, 2003, pp. 267-279

[12] Ricky Ryssel, Thomas Ritter, Hans Georg Gemünden, "The Impact of Information Technology Deployment on Trust, Commitment and Value Creation in Business Relationships" , 3rd ed., vol. 19. Journal of Business \& Industrial Marketing, 2004, pp. 197 - 207

[13] Sullivan. J,Vardell. T, Suddeth. B. N., Vojadni A , "Interruption Costs, Customer Satisfaction and Expectations for Service Reliability", 1st ed. vol. 24. Journal of the Academy of Marketing Science, 1996, pp. 3-16

[14] Brown, L.G, "Convenience in services marketing", Winter., vol. 4. Journal of Services Marketing, 1990, pp. 53-59

[15] Grönroos, C, “A service quality model and its marketing implications", 4th ed., vol. 18. European Journal of Marketing,, 1984, pp. 36-44. 